\title{
Prevalence of depression and anxiety, and their association with quality of life and physical activity in South Asian patients undergoing coronary artery bypass graft surgery.
}

\author{
Faraz Farooqui ${ }^{1}$, Monika Jha ${ }^{1}$, Harsimarpreet Kaur ${ }^{1}$, Aman Agarwal ${ }^{1}$, Milind Hote ${ }^{1}$, \\ Velayoudam Devagourou ${ }^{1}$, Ravindra Pandey ${ }^{1}$, Shiv Choudhary ${ }^{1}$, and Gautam Sharma ${ }^{1}$ \\ ${ }^{1}$ All India Institute of Medical Sciences
}

September 10, 2020

\begin{abstract}
Aims: To determine the prevalence of depression and anxiety in Indian patients undergoing CABG surgery and their relationship to physical activity and quality of life. Methods: 121 patients undergoing CABG surgery between November 2017 and May 2019 were included. The Hospital Anxiety and Depression Scale (HADS) was employed for the assessment of depression and anxiety. Health-related quality of life was assessed using the SF-36 questionnaire. The short form of the International Physical Activity Questionnaire (IPAQ) was used for assessment of physical activity. Participants were categorized into high, moderate or low physical activity. Results: The overall prevalence (95\% CI) of depression and anxiety was 70.5\% (0.61-0.78) and 64.6\% (0.55-0.73) respectively. When a cut-off score of 11 instead of 8 was used on the HADS [Borderline cases excluded (HADS score $8-10)]$, the prevalence of depression and anxiety was $31.3 \%(0.22-0.40)$ and $40.7 \%(0.31-0.50)$ respectively. Patients with low levels of physical activity had a higher prevalence of depression and anxiety $(\mathrm{p}<0.05)$. Patients with depression demonstrated a worse quality of life compared to those without depression in all domains measured by the SF-36 questionnaire. Among patients with anxiety, quality of life was worse in four out of the eight domains measured by the SF-36 questionnaire. Conclusion: Indian patients undergoing CABG surgery have a high prevalence of depression and anxiety. Patients with depression and anxiety were found to have low physical activity and poor quality of life when compared to their counterpart. Keywords: CABG; depression; anxiety; quality of life; physical activity.
\end{abstract}

\section{INTRODUCTION:}

Coronary Artery Disease is an important cause of morbidity and mortality in the world. Clustering of chronic diseases is common in patients with coronary artery disease (CAD). Chronic diseases such as diabetes, hypertension, dyslipidemia etc., have been well studied in the context of CAD. However, psychiatric comorbidity especially depression and anxiety, is frequently overlooked in these patients. The proportion of CAD patients suffering from psychiatric co-morbidity is not insignificant. Previous studies have reported the prevalence of depression to be about $20-40 \%$ in patients with $\operatorname{CAD}(1)$. Similarly, anxiety has been reported in 20-30\% of patients following an acute coronary syndrome (ACS)(2,3).Psychiatric co-morbidity has also found to be prevalent in cardiovascular disorders other than CAD. Depression and anxiety in chronic cardiovascular conditions such as chronic heart failure (CHF) are being increasingly recognized $(4,5)$.

Patients of CAD referred for coronary artery bypass graft (CABG) surgery constitute a special population. Most of these patients are limited in their activity by angina which is attributable to their multivessel coronary artery disease. In addition, these patients are confronted with the problem of polypharmacy due to multiple antianginal medications apart from other agents which include but are not limited to antiplatelets, statins, antidiabetic and antihypertensive medications. Compounding these issues is the stress of an impending major surgery. All of these factors may add significantly to the burden of psychiatric co-morbidity in this 
specific group of patients. Pre-operative depression and anxiety have been shown to be associated with worse outcomes post CABG surgery(6-9). In addition, untreated depression and anxiety hamper efforts at complete cardiac rehabilitation following CABG. Identification of co morbid psychiatric disorders is therefore of vital importance in patients undergoing CABG surgery. With an increasing burden of CAD in developing countries, there has been a rise in the number of CABG surgeries performed each year. Nearly 150,000 CABG surgeries are performed in India every year. Despite these large numbers, there is little available Indian data on the prevalence of depression and anxiety in patients undergoing CABG surgery. The present study was performed to determine the prevalence of depression and anxiety in Indian patients undergoing CABG surgery and their relationship to physical activity and quality of life.

\section{METHODS:}

\section{Study Population}

The present study was a quantitative research approach with a cross-sectional study design. Patients were recruited from the Cardiothoracic and Neurosciences Centre (CNC) out-patient department at the All India Institute of Medical Sciences, New Delhi which is a tertiary-care referral centre in North India. Individual informed consent was obtained from all the participants at enrolment in the study. Data was collected during hospital admission, two to seven days prior to elective CABG surgery. One hundred and twenty-one patients were included in the study. Study population included patients between 35 to 65 years of age with established CAD (double or triple vessel disease) planned for elective CABG surgery. Patients undergoing emergency CABG surgery or CABG surgery with valve replacement, patients with LV dysfunction (LVEF $<30 \%$ ), renal dysfunction and known neuropsychiatric illnesses were excluded from the study. Baseline demographic and clinical data was obtained from all the patients.

\section{Assessment of Depression, Anxiety, Quality of Life and Physical Activity}

The Hospital Anxiety and Depression Scale (HADS) was employed for the assessment of depression and anxiety(10). Individual confidentiality was maintained. This is an easily administered questionnaire consisting of 14 questions ( 7 questions pertaining to depression and 7 questions pertaining to anxiety). Each question is answered by the selection of one of four options which are scored from 0-3. A score of [?] 8 was used to define cases of depression or anxiety.

Health-related quality of life was assessed using the SF-36 questionnaire(11,12). It is a 36-item questionnaire that measures physical functioning, role limitation due to physical health, bodily pain, general health, energy or vitality, social functioning, role limitation due to emotional problems and mental health. The test was administered by well-trained nursing staff. Average time taken to administer the test was kept equal for all patients. The eight scaled scores were given a value of 0-100 with lower scores representing more disability.

The short form of the International Physical Activity Questionnaire (IPAQ) was used for assessment of physical activity of patients(13). This consists of seven questions regarding vigorous physical activity, moderate physical activity, walking and sitting in the preceding one week. The participants were categorized into high, moderate or low physical activity.

\section{Statistical Analysis:}

Data was recorded on a predesigned proforma and managed on an excel spreadsheet. All the entries were checked for any possible keyboard errors. Categorical variables were summarized as frequency (percentage). Quantitative variables were assessed for approximate normality and summarized as mean $\pm \mathrm{SD}$. In this study we defined four outcomes: depression, anxiety, both depression and anxiety and depression and/or anxiety. Chi square test was used to compare frequencies across various socio-demographic characteristics for each of the four outcomes separately. Independent sample t-test was used to compare mean values across categories. Odds ratio (95\% CI) was computed to determine the strength of association between each of the socio-demographic characteristics and the four outcomes using binary logistic regression. To determine the independent role of each factor with each of the four outcomes i.e. depression, anxiety, depression and/or anxiety, and depression and anxiety, stepwise multivariable logistic regression analysis was used to compute 
adjusted odds ratio (95\% CI). Statistical software Stata 14.2 was used for data analysis. In this study, p-value $<0.05$ has been considered as statistically significant.

\section{RESULTS:}

A total of 121 patients were included in this study between November 2017 and May 2019.The baseline socio-demographic and clinical variables are presented in Table 1. The mean age of study participants was $54.9 \pm 7.5$ years. The predominant study participants were male [83.5\% (95\% CI, 0.75-0.89)]. Nearly threefourths of the patients were either overweight or obese. The overall prevalence (95\% CI) of depression in the study population was $70.5 \%(0.61-0.78)$. On the other hand, anxiety was present in $64.6 \%(0.55-0.73)$ of patients. When a cut-off score of 11 instead of 8 was used on the HADS for diagnosis of depression/ anxiety [Borderline cases excluded (HADS score 8-10)], the prevalence of depression and anxiety was 31.3\% (0.22-0.40) and $40.7 \%$ (0.31-0.50) respectively. $51.2 \%$ (0.41-0.60) of patients had both depression and anxiety. However, when borderline cases (HADS score 8-10) were excluded, both depression and anxiety were present in 19\% (0.12-0.27) of patients. The prevalence and characteristics of patients with depression and anxiety are presented in Table 2. Obese individuals were more likely to have depression compared to those individuals with a normal weight (OR 5.7; 95\% CI, 1.2-25.5) [Table 3]. The odds of anxiety were higher in patients with dyslipidemia (OR 5.3; 95\% CI, 1.9-14.3) compared to those with absence of dyslipidemia (Table 3). The relationship between physical activity and depression/ anxiety is shown in Figure 1. Patients with low levels of physical activity had a higher prevalence of depression and anxiety $(\mathrm{p}<0.05)$. A similar relationship was not observed in those with moderate and high levels of physical activity. Patients with depression demonstrated a worse quality of life compared to those without depression in all domains measured by the SF-36 questionnaire (Figure 2). Among patients with anxiety, quality of life was worse in four out of the eight domains (physical functioning, vitality, mental health and general health measured by the SF-36 questionnaire (Figure 2).

\section{DISCUSSION}

Psychiatric co-morbidity in the form of depression and anxiety is not uncommon in patients with CAD. The INTERHEART study results have drawn attention to the role of psychosocial factors in CAD(14). Several studies have demonstrated that depression and anxiety are associated with worse outcomes in CAD patients(15-18). These factors may be even more prevalent in patients referred for CABG surgery given the severity of CAD and the anticipated major surgery. This makes identification of depression and anxiety in these patients an essential part of preoperative evaluation. To our knowledge, the present study is the largest Indian study of psychiatric co-morbidity in patients undergoing CABG.

The prevalence of depression and anxiety in our population was $70.5 \%$ and $64.6 \%$ respectively. Even after exclusion of borderline cases, the prevalence of depression and anxiety remained high at $31.3 \%$ and $40.7 \%$ respectively. Interestingly, $19 \%$ of patients were found to have both depression and anxiety, even after the exclusion of borderline cases. Previous studies have evaluated depression and anxiety in patients being referred for CABG surgery. Different questionnaires which are self-reported by the patient have been used for this purpose(10,19-22). These questionnaires have variable sensitivity and specificity(23). Pirraglia and colleagues studied 237 patients undergoing CABG surgery and found the prevalence of pre-operative depression to be $43.1 \%$. Similarly, other studies have shown a prevalence of pre-operative depression ranging from 27 to $47 \%(24,25)$. Pre-operative anxiety has also been evaluated in patients undergoing CABG. Out of 142 patients undergoing CABG surgery, Krannich et al. found preoperative anxiety in $34 \%$ of patients(26). Younger patients had more anxiety compared to older patients and showed a decline in symptoms following surgery, in contrast to older patients who did not demonstrate a similar change. In a study of 172 patients, Gallagher et al. reported anxiety in $40.6 \%$ patients(27). Data from India on preoperative anxiety and depression is scant. In a small study by Chaudhury et al. from a tertiary hospital in India, preoperative anxiety and depression was reported in $43.3 \%$ and $30 \%$ before CABG surgery(28). These numbers indicate a significant burden of depression and anxiety in patients undergoing CABG.

Preoperative anxiety and depression are not limited to CABG surgery alone and are frequently diagnosed in 
patients undergoing elective non-cardiac surgery. Using HADS, Kuzminskaitė and colleagues demonstrated preoperative anxiety in $12.6 \%$ of patients undergoing elective non-cardiac surgery(29). The burden of multiple chronic risk factors and previous acute coronary syndromes in a large proportion of patients undergoing CABG surgery may place this subset of patients at a relatively higher risk of preoperative anxiety and depression compared to patients undergoing non-cardiac surgery. Most studies evaluating preoperative anxiety have administered questionnaires on the preoperative day(30,31). Procedure related anxiety related to impending surgery may theoretically be highest on the day preceding surgery. In the present study however, the questionnaires were administered two to seven days prior to elective CABG surgery.

Depressed patients were found to have a worse quality of life compared to those without depression in our study. This was true for all domains measured by the SF-36 questionnaire. We also found that patients with anxiety had a worse quality of life compared to those without anxiety, in the domains of physical functioning, vitality, mental health and general health. Our findings are in agreement with existing literature. In a large study of 1282 patients with stable CAD, Spertus and colleagues found that co-morbid depression was associated with a worse angina-specific functional status, more frequent anginal episodes and a worse quality of life(24). Similar results were demonstrated by Ruo et al., who showed that depressive symptoms were associated with a greater symptom burden, worse health-related quality of life (HRQOL), greater physical limitation and poorer overall health(33). It has been demonstrated previously that depression predicted poor functional improvement after CABG surgery compared to traditional measures of cardiovascular disease severity $(34)$.

We also found that patients with low levels of physical activity were more often depressed and anxious. This was not the case in those with moderate and high levels of physical activity. Patients with multivessel CAD referred for CABG surgery often have limitation of moderate and high levels of physical activity on account of exercise limiting angina. A large proportion of these patients are therefore condemned to low levels of physical activity. The additional burden of psychiatric co-morbidity in the form of depression and anxiety in these patients is associated with worse outcomes if left untreated $(35,36)$.

Preoperative depression and anxiety have been demonstrated previously to increase post-operative morbidity following CABG surgery(6-9,37). Preoperative identification of these patients allows maximization of efforts towards the treatment of depression and anxiety. Early interventions aimed at treatment of these disorders have been associated with a reduction in length of hospital stay, analgesic use, and postsurgical morbidity(3841). Treatment measures not only include non-pharmacologic measures such as cognitive behavior therapy (CBT) but also pharmacologic therapy in some of these patients. Although, psychosocial interventions constitute an essential component of cardiac rehabilitation programs, patients with depression and anxiety may not be sufficiently motivated to actively take part or continue with these programs in the post-operative period(42). Early identification and treatment of co-morbid depression and anxiety is therefore essential towards improving outcomes post-CABG surgery.

There are a few limitations of our study. Our study included a small number of patients. Since the data was from a single tertiary center, it may not be reflective of the wider population of CAD patients undergoing CABG. Most of the study participants were male patients. Female patients constituted only a small proportion of the study population. This is important because depression and anxiety in patients with cardiovascular disease has been known to affect women more than men(43). Data on income status and pill burden was not collected from the study participants. These factors may have had a bearing on the HADS scores. In the present study we did not follow up patients after CABG surgery. Therefore, the impact of successful CABG surgery on HADS scores could not be assessed.

In conclusion, we found a significant prevalence of anxiety and depression in patients undergoing CABG surgery. In addition, depression and anxiety were associated with a worse quality of life in these patients. There was a high prevalence of depression and anxiety among patients with low level of physical activity who were referred for CABG surgery. It is important to evaluate patients undergoing CABG for co-morbid depression and anxiety. Pre-operative identification of depression and anxiety allows focused efforts to be directed towards treating these disorders, which if untreated have been associated with worse postoperative 
outcomes.

Acknowledgments: The authors acknowledge the role of highly trained staff nurses (Ms. Jincy Alex and Ms. Pasang Lamo) in data acquisition.

Ethical approval: This study was approved by the ethics committee of All India Institute of Medical Sciences (AIIMS)

Conflict of interest: The authors declare that they do not have any conflicts of interest.

\section{Authors's contribution:}

Concept/Design: Dr Gautam Sharma, Dr. Harsimarpreet kaur, Dr. Monika Jha, Dr. Faraz Ahmed Farooqui

Drafting article: Dr. Faraz Ahmed Farooqui, Dr Gautam Sharma, Dr. Monika Jha,

Critical revision of article: Dr. Shiv Choudhary, Dr. Milind P. Hote, Dr. Velayoudam. Devagourou, Dr. R. M Pandey, Dr. Gautam Sharma, Dr. Faraz Ahmed Farooqui, Dr. Monika Jha

Approval of article: Dr. Shiv Choudhary, Dr. Milind P. Hote, Dr. Velayoudam Devagourou, Dr. R. M Pandey, Dr. Gautam Sharma

Statistics: Mr. Aman Agarwal, Dr. R.M Pandey

Data collection: Dr. Monika Jha, Dr. Faraz Ahmed Farooqui.

\section{References:}

1. Celano CM, Huffman JC. Depression and cardiac disease: a review. Cardiol Rev. 2011 Jun;19(3):130-42.

2. Grace SL, Abbey SE, Irvine J, Shnek ZM, Stewart DE. Prospective examination of anxiety persistence and its relationship to cardiac symptoms and recurrent cardiac events. Psychother Psychosom. 2004 Dec;73(6):344-52.

3. Hanssen TA, Nordrehaug JE, Eide GE, Bjelland I, Rokne B. Anxiety and depression after acute myocardial infarction: an 18-month follow-up study with repeated measures and comparison with a reference population. Eur J Cardiovasc Prev Rehabil. 2009 Dec;16(6):651-9.

4. Celano CM, Villegas AC, Albanese AM, Gaggin HK, Huffman JC. Depression and Anxiety in Heart Failure: A Review. Harv Rev Psychiatry. 2018 Aug;26(4):175-84.

5. Rutledge T, Reis VA, Linke SE, Greenberg BH, Mills PJ. Depression in heart failure a meta-analytic review of prevalence, intervention effects, and associations with clinical outcomes. J Am Coll Cardiol. 2006 Oct 17;48(8):1527-37.

6. Stengrevics S, Sirois C, Schwartz CE, Friedman R, Domar AD. The prediction of cardiac surgery outcome based upon preoperative psychological factors. Psychology \& Health. 1996 May 1;11(4):471-7.

7. Saur CD, Granger BB, Muhlbaier LH, Forman LM, McKenzie RJ, Taylor MC, et al. Depressive symptoms and outcome of coronary artery bypass grafting. Am J Crit Care. 2001 Jan;10(1):4-10.

8. Scheier MF, Matthews KA, Owens JF, Schulz R, Bridges MW, Magovern GJ, et al. Optimism and rehospitalization after coronary artery bypass graft surgery. Arch Intern Med. 1999 Apr 26;159(8):829-35.

9. Connerney I, Shapiro PA, McLaughlin JS, Bagiella E, Sloan RP. Relation between depression after coronary artery bypass surgery and 12-month outcome: a prospective study. Lancet. 2001 Nov $24 ; 358(9295): 1766-71$.

10. Zigmond AS, Snaith RP. The hospital anxiety and depression scale. Acta Psychiatr Scand. 1983 Jun;67(6):361-70. 
11. Ware JE, Sherbourne CD. The MOS 36-item short-form health survey (SF-36). I. Conceptual framework and item selection. Med Care. 1992 Jun;30(6):473-83.

12. McHorney CA, Ware JE, Raczek AE. The MOS 36-Item Short-Form Health Survey (SF-36): II. Psychometric and clinical tests of validity in measuring physical and mental health constructs. Med Care. 1993 Mar;31(3):247-63.

13. Craig CL, Marshall AL, Sjöström M, Bauman AE, Booth ML, Ainsworth BE, et al. International physical activity questionnaire: 12-country reliability and validity. Med Sci Sports Exerc. 2003 Aug;35(8):1381-95.

14. Yusuf S, Hawken S, Ounpuu S, Dans T, Avezum A, Lanas F, et al. Effect of potentially modifiable risk factors associated with myocardial infarction in 52 countries (the INTERHEART study): case-control study. Lancet. 2004 Sep 11;364(9438):937-52.

15. Watkins LL, Koch GG, Sherwood A, Blumenthal JA, Davidson JRT, O'Connor C, et al. Association of anxiety and depression with all-cause mortality in individuals with coronary heart disease. J Am Heart Assoc. 2013 Mar 19;2(2):e000068.

16. Nicholson A, Kuper H, Hemingway H. Depression as an aetiologic and prognostic factor in coronary heart disease: a meta-analysis of 6362 events among 146538 participants in 54 observational studies. Eur Heart J. 2006 Dec;27(23):2763-74.

17. Martens EJ, de Jonge P, Na B, Cohen BE, Lett H, Whooley MA. Scared to death? Generalized anxiety disorder and cardiovascular events in patients with stable coronary heart disease:The Heart and Soul Study. Arch Gen Psychiatry. 2010 Jul;67(7):750-8.

18. Roest AM, Zuidersma M, de Jonge P. Myocardial infarction and generalised anxiety disorder: 10-year follow-up. Br J Psychiatry. 2012 Apr;200(4):324-9.

19. Beck AT, Ward CH, Mendelson M, Mock J, Erbaugh J. An inventory for measuring depression. Arch Gen Psychiatry. 1961 Jun;4:561-71.

20. Andresen EM, Malmgren JA, Carter WB, Patrick DL. Screening for depression in well older adults: evaluation of a short form of the CES-D (Center for Epidemiologic Studies Depression Scale). Am J Prev Med. 1994 Apr;10(2):77-84.

21. Hare DL, Davis CR. Cardiac Depression Scale: validation of a new depression scale for cardiac patients. J Psychosom Res. 1996 Apr;40(4):379-86.

22. Shi WY, Stewart AG, Hare DL. Major depression in cardiac patients is accurately assessed using the cardiac depression scale. Psychother Psychosom. 2010;79(6):391-2.

23. Hare DL, Toukhsati SR, Johansson P, Jaarsma T. Depression and cardiovascular disease: a clinical review. Eur Heart J. 2014 Jun 1;35(21):1365-72.

24. Burker EJ, Blumenthal JA, Feldman M, Burnett R, White W, Smith LR, et al. Depression in male and female patients undergoing cardiac surgery. Br J Clin Psychol. 1995 Feb;34 ( Pt 1):119-28.

25. McKhann GM, Borowicz LM, Goldsborough MA, Enger C, Selnes OA. Depression and cognitive decline after coronary artery bypass grafting. Lancet. 1997 May 3;349(9061):1282-4.

26. Krannich J-HA, Weyers P, Lueger S, Herzog M, Bohrer T, Elert O. Presence of depression and anxiety before and after coronary artery bypass graft surgery and their relationship to age. BMC Psychiatry. 2007 Sep 12;7:47.

27. Gallagher R, McKinley S. Stressors and anxiety in patients undergoing coronary artery bypass surgery. Am J Crit Care. 2007 May;16(3):248-57.

28. Chaudhury S, Sharma S, Pawar A, Kumar B, Srivastava MK, Sudarsanan S, et al. Psychological Correlates of Outcome after Coronary Artery Bypass Graft. Med J Armed Forces India. 2006 Jul;62(3):220-3. 
29. Kuzminskaitė V, Kaklauskaitė J, Petkevičiūtè J. Incidence and features of preoperative anxiety in patients undergoing elective non-cardiac surgery. Acta Med Litu. 2019;26(1):93-100.

30. Jawaid M, Mushtaq A, Mukhtar S, Khan Z. Preoperative anxiety before elective surgery. Neurosciences (Riyadh). 2007 Apr;12(2):145-8.

31. Pokharel K, Bhattarai B, Tripathi M, Khatiwada S, Subedi A. Nepalese patients' anxiety and concerns before surgery. J Clin Anesth. 2011 Aug;23(5):372-8.

32. Spertus JA, McDonell M, Woodman CL, Fihn SD. Association between depression and worse diseasespecific functional status in outpatients with coronary artery disease. Am Heart J. 2000 Jul;140(1):105-10.

33. Ruo B, Rumsfeld JS, Hlatky MA, Liu H, Browner WS, Whooley MA. Depressive symptoms and healthrelated quality of life: the Heart and Soul Study. JAMA. 2003 Jul 9;290(2):215-21.

34. Mallik S, Krumholz HM, Lin ZQ, Kasl SV, Mattera JA, Roumains SA, et al. Patients with depressive symptoms have lower health status benefits after coronary artery bypass surgery. Circulation. 2005 Jan $25 ; 111(3): 271-7$.

35. Celano CM, Millstein RA, Bedoya CA, Healy BC, Roest AM, Huffman JC. Association between anxiety and mortality in patients with coronary artery disease: A meta-analysis. Am Heart J. 2015 Dec;170(6):110515.

36. Lichtman JH, Froelicher ES, Blumenthal JA, Carney RM, Doering LV, Frasure-Smith N, et al. Depression as a risk factor for poor prognosis among patients with acute coronary syndrome: systematic review and recommendations: a scientific statement from the American Heart Association. Circulation. 2014 Mar 25;129(12):1350-69.

37. Perski A, Feleke E, Anderson G, Samad BA, Westerlund H, Ericsson CG, et al. Emotional distress before coronary bypass grafting limits the benefits of surgery. Am Heart J. 1998 Sep;136(3):510-7.

38. Perski A, Osuchowski K, Andersson L, Sanden A, Feleke E, Anderson G. Intensive rehabilitation of emotionally distressed patients after coronary by-pass grafting. J Intern Med. 1999 Sep;246(3):253-63.

39. Karlsson I, Berglin E, Pettersson G, Larsson PA. Predictors of chest pain after coronary artery bypass grafting. Scand Cardiovasc J. 1999;33(5):289-94.

40. Mumford E, Schlesinger HJ, Glass GV. The effect of psychological intervention on recovery from surgery and heart attacks: an analysis of the literature. Am J Public Health. 1982 Feb;72(2):141-51.

41. Ashton C, Whitworth GC, Seldomridge JA, Shapiro PA, Weinberg AD, Michler RE, et al. Self-hypnosis reduces anxiety following coronary artery bypass surgery. A prospective, randomized trial. J Cardiovasc Surg (Torino). 1997 Feb;38(1):69-75.

42. Pignay-Demaria V, Lespérance F, Demaria RG, Frasure-Smith N, Perrault LP. Depression and anxiety and outcomes of coronary artery bypass surgery. Ann Thorac Surg. 2003 Jan;75(1):314-21.

43. Gulati M, Buffomante AA, Wenger NK. Depression and Anxiety in Women with Heart Disease. Curr Cardiovasc Risk Rep. 2016 Sep 9;10(10):32.

\section{Hosted file}

Figures.docx available at https://authorea.com/users/355058/articles/478449-prevalence-ofdepression-and-anxiety-and-their-association-with-quality-of-life-and-physical-activityin-south-asian-patients-undergoing-coronary-artery-bypass-graft-surgery

\section{Hosted file}

Tables.docx available at https://authorea.com/users/355058/articles/478449-prevalence-ofdepression-and-anxiety-and-their-association-with-quality-of-life-and-physical-activity- 
in-south-asian-patients-undergoing-coronary-artery-bypass-graft-surgery 